\section{House improvements and community participation in the control of Triatoma dimidiata re-infestation in Jutiapa, Guatemala}

\author{
Melhorias habitacionais com participação comunitária \\ no controle da re-infestação por Triatoma dimidiata \\ em Jutiapa, Guatemala
}

Carlota Monroy 1

Dulce Maria Bustamante 1

Sandy Pineda 1

Antonieta Rodas 1

Xochitl Castro 1

Virgilio Ayala 2

Javier Quiñónes 2

Bárbara Moguel 1

\section{Introduction}

The deterioration or absence of plaster walls in houses and poor hygienic conditions are the most important risk factors for indoor Triatoma dimidiata infestation in Guatemala. A crossdisciplinary study was conducted addressing T. dimidiata infestation, household hygiene, and housing construction. The study focused on local materials and cultural aspects (including gender roles) that could lead to long-term improvements in wall construction. A new plaster mix for walls was developed on the basis of laboratory studies on construction materials recommended by local villagers. Four villages with persistent (postspraying) T. dimidiata infestation were studied. In two villages, an ecosystem approach was implemented, and the homeowners conducted wall improvements and household sanitation with the support of the interdisciplinary team (the ecosystem intervention). In the other two villages, a vector control approach based on insecticide spraying was adopted (traditional intervention). Both interventions were associated with a reduction in T. dimidiata infestation, but only the ecosystem approach produced important housing improvements (sanitation and wall construction) capable of preventing T. dimidiata re-infestation in the long term.

Chagas Disease; Consumer Participation; Housing Sanitation; Housing
Triatoma dimidiata is currently the main vector of Trypanosoma cruzi, the causative agent of Chagas disease, in Guatemala, El Salvador, Nicaragua and Costa Rica, and the second most important vector in Honduras and Colombia. This species is not a candidate for eradication from Central America due to its opportunistic use of habitats, dispersal capacity, and genetic heterogeneity 1,2,3,4,5. T. dimidiata populations also have different degrees of domesticity, a relevant factor that affects the efficacy of control strategies against this vector throughout its distribution 6 . Thus, the Central America Initiative for the interruption of the vectorial transmission of Chagas disease set as its objective to significantly reduce the domestic infestations of T. dimidiata in the region 7 . In Guatemala, the use of pyrethroid insecticides was the main strategy followed to achieve this goal 8,9 .

When chemical control of T. dimidiata is carried out, post-spraying reinfestation often occurs. In some areas of Yucatan, Mexico, adult insects were detected in houses within four months of chemical control ${ }^{10}$. In Guatemala, single sprayings reduced the domestic infestations in the departments of Zacapa 8 and Jutiapa 9 . But recent evaluations in Jutiapa showed that $T$. dimidiata domestic infestations doubled in a period of 33 months (from $<5 \%$ to $12.1 \%$ ) in some villages where a single spraying was applied 11 . 
Reinfestation of houses could be caused by residual populations that are not affected by the insecticides or by insect dispersion from other foci that could include the peridomicile and sylvatic environments or neighboring villages 2,12 . This is supported by genetic studies that have shown that populations from adjacent villages are panmictic 13 and by direct observations of flying or walking bugs made in northern Guatemala 4 . Indirectly, dispersal is suggested by persistent infestations in geographically clustered villages 11 . New approaches to long term vector control need to consider prevention of reinfestation from internal and external sources.

Within Guatemala, the department of Jutiapa has a set of special conditions: it presented the highest level of triatomine infestation (percentage of infested houses) and dispersion (percentage of infested villages) at $34.5 \%$ and $85.7 \%$ respectively 14 ; approximately $10 \%$ of the bugs in the area have been reported as infected with $T r$. cruzi 15 ; and $4.2 \%$ of school-aged children (10.1 \pm 2.2 years old) had positive serology for Tr. cruzi 16 . The infestation by T. dimidiata in Jutiapa is persistent, and up to three rounds of insecticide sprayings were necessary to reduce it to below $5 \%$ in some areas. These repeated control actions still need to be evaluated in order to determine their long-term effectiveness 11.

In order to achieve long-term effectiveness, a wide range of options have been proposed but most of them require enormous amounts of financial investment. But in some cases, money-saving approaches have been proposed such as that put forward by Zeledón \& Rojas 12 that recommends a simple "ecological control" method that has considerably reduced domestic T. dimidiata infestations in Costa Rica. The method consists in removing from houses those objects and materials that could serve as hiding places for the bug. Another study conducted in southeastern Guatemala demonstrated that wall improvements made with local and inexpensive materials were effective in decreasing bug infestations 17 .

The challenge with approaches such as improved wall plastering is how to guarantee that they are put into practice by the affected people and incorporated into their daily lives. This paper presents the main results of a transdisciplinary study in Jutiapa, Guatemala that investigated local house construction practices, overall house hygiene conditions and environmental factors that could affect triatomine infestation. The results of the investigation could serve as a foundation for a control strategy centered on community participation to improve wall plastering. We discuss the implications for T. dimidiata domes- tic and peridomestic control in Guatemala and Central America.

\section{Methods}

The study was conducted in the department of Jutiapa, located in the Chagas endemic region of southeastern Guatemala, from January 2004 to December 2006. Four villages, La Brea, El Tule, El Sillon, and La Perla (total 664 houses) were selected based upon their persistent triatomine reinfestation status, their similarity in house construction practices and ecological conditions (dry forest), similar ethnic background (Spanish speaking, non-Mayan Latinos) and ways of life (subsistence agriculture), equivalent number of houses and distance between the villages. All these villages had been sprayed against triatomines at least once by Guatemala's Ministry of Health.

The four villages were selected to implement and compare two different intervention approaches to reduce triatomine infestation and prevent reinfestation. The first intervention approach was named 'ecosystemic' and it was applied in the villages of El Tule and La Brea (Quesada Municipality). The second control intervention was named "traditional" and was applied in the villages of El Sillon and La Perla (Yupiltepeque Municipality). The selection of the ecosystemic villages was based on the researchers' previous experiences of La Brea village with the World Health Organization's Special Programme for Research and Training in Tropical Diseases (TDR-WHO project).

Before the implementation of any approach, all houses (90-95\%) in each village were surveyed to obtain basic information relating to entomology and house conditions. The same surveys were conducted after the interventions and the information obtained before and after was used to perform comparison tests. Surveys about the people's traditional house construction practices were also conducted; this information was to be important if house improvements were to be promoted among the community in a way compatible with their traditions.

\section{Entomological and house condition surveys}

The surveys were conducted in a total of 644 houses in 2004 (before the interventions) and 634 houses in 2006 (after the interventions), corresponding to $95-97 \%$ of all houses in the four villages (664).

The entomological surveys consisted of searching for triatomines inside and around the 
domestic and peridomestic structures. For each family compound (domestic and peridomestic structures), bugs were searched for half an hour by two people using flashlights and looking inside cracks in walls, behind loose plaster, under mattresses, behind furniture, and in other microenvironments suitable for sheltering bugs. The entomological information was used to calculate the entomological indices for the villages: infestation, colonization, and crowding 18.

The house condition surveys evaluated: (a) material comfort, cleanliness, cluttering; and (b) conditions wall construction materials and plaster. The kind of house improvements or repairs that people habitually make was also recorded.

Wall plaster conditions, dirt or cement floor, hygiene conditions, order inside the house and family economic conditions were the criteria used to classify houses as A, B, or C, as follows:

- House category A: all walls plastered, and plaster in good conditions, cement floor in all rooms, floor and walls clean, with electro domestic appliances, order and hygiene conditions good.

- House category B: not all walls were plastered or some plasters deteriorated, poor hygiene and order inside the house (dust, garbage on the floor or spider webs on the walls), dirt floors in some areas, few domestic appliances.

- House category C: Most walls without plaster or plaster deteriorated (cracks, holes), dirt floor in bedrooms, dust, garbage on the floor, spider webs on walls, cluttered, few or no electric appliances.

House construction practices and new plaster mixture

Improvements to a house's living conditions (especially wall plaster) by the population was envisioned as the central component of the ecosystemic intervention approach (described below). Thus, before implementing this type of intervention it was important to identify the materials and the traditional methods used for wall plastering to later test them and improve them. Personal interviews were carried out with community leaders and house owners, and local plaster materials that were pointed out by the community were collected and transported to the Technology Materials Laboratory and Ecomaterials Department of Engineering Research Center (CII), at San Carlos University, Guatemala. Several tests such as: pull out, capillarity, particle side analysis of soils, liquid limit of soils, plastic limit and plasticity index of soils (as described by the American Association of State Highway and Transportation Officials - AASHTO - and Centre Scientifique et Technique du Bati- ment - CSTB) 19,20 were performed to determine the mix of materials that would produce an inexpensive and durable wall plaster. An improved mixture (not described here) generally consisted of one part local soil (clay) and three parts sand. River sand is the best since particle size is very important.

\section{Ecosystemic and traditional control interventions}

The ecosystemic intervention consisted of the research group promoting: community participation, basic knowledge of Chagas disease vectors and risk factors, plastering walls with local materials (performed by the house owner), one insecticide application (by personnel from the Ministry of Health); promotion of reforestation in backyards with fruit plants and non-stinging bees (Maya bees), and promotion and technification. The traditional approach, on the other hand, was limited to disseminating basic knowledge about Chagas disease and one insecticide application.

The traditional intervention was centered on house insecticide spraying with Deltametrin, 5\% water-soluble powder (at $25 \mathrm{mg}$ of active ingredient per $\mathrm{m}^{2}$ ), that was applied by regular staff from the Ministry of Health in the domestic and peri-domestic environments. In the ecosystemic approach, insecticide application was performed by the same personnel in the same way as in the traditional approach.

Visits to villages by the research group and personnel from the Ministry of Health occurred for between ten and 12 months a year in the ecosystemic villages and for two to three months a year in the traditional approach. In one year each house was visited once or twice in the traditional approach villages and seven to eight times in each house in the ecosystemic villages. The constant visits to the communities formed a confidence bond between the researchers and inhabitants of the ecosystemic villages.

Sand was an important material used in the new plaster formulation and was provided to those households that agreed to carry out house improvements. The Municipality of Quesada donated sand and transportation (10 trucks) for the village of El Tule and sand for La Brea, where the project covered transportation costs. The trucks left the sand in selected backyards, from which community collaborators organized distribution to house owners. The sand was collected from rivers near to the Quesada region (3 to $11 \mathrm{~km}$ away).

The group of engineers, architects, and anthropologist and community volunteers were responsible for teaching house inhabitants about 
wall improvements, how to mix materials and how to apply the plaster. Materials selected previously from the pilot tests (not described here) were suggested to be used in a mixture with sand from a nearby river (Rio Paz).

In the ecosystemic villages the research group was joined by community volunteers and public health workers and visited all houses (house by house) talking about the Chagas disease vector and risk factors. The informal talks were oriented to educate the population on how they could prevent triatomine infestation (better house hygiene, reduced cluttering inside houses, etc.) and ensure that all family members, particularly woman and children, were present at the time. The families asked specific questions about the disease or talked about community problems related to house construction, the presence of bugs, domestic animal concerns or experiences with Chagas disease.

\section{Insecticide sprayings}

The four villages were sprayed during this study during February/March 2005 as part of the research protocol. Before our intervention all villages had received at least one insecticide application as part of the regular National Control Campaign.

By the end of the intervention the villages of La Brea and El Sillon had received four insecticide applications, La Perla three and El Tule two. Before the intervention two triatomine species were found, T. dimidiata and T. nitida, whereas after the intervention only $T$. dimidiata was recorded.

The number of houses sprayed per village during this study were as follows: El Tule, 216; La Brea, 133; El Sillon, 160; and La Perla, 135. Store rooms, churches, schools, chicken coops, doghouses, and backyard structures were sprayed in the four villages.

\section{Statistical analysis}

The information from the 550 houses that were surveyed in both the initial and final surveys, and for which complete information on house category and wall plastering was available, was used to perform comparison tests. The McNemar test 21 for matched pairs (the information of one house before and after constitutes a matched pair) was applied to the study, measuring changes in the proportion of category $\mathrm{C}$ houses and changes in the proportion of houses that were completely plastered. Tests were performed for each village separately and a significance level (alpha $=0.05$ ) was established.

\section{Results}

\section{Construction practices before} the intervention

The plastering of walls was the most frequently reported type of house improvement made by the population (Figure 1). From surveys it was determined that among those that live in category $\mathrm{B}$ and $\mathrm{C}$ houses, women are the ones that plaster with local materials and their bare hands (no tools). This practice is called "revocado" and it is not considered formal construction but a cosmetic renewal of the house since it does not last long. In some of the category A houses a different plaster named "repello" is used and it is made from cement and sand and is applied with tools by qualified construction workers.

\section{Changes in house category and house plastering after the interventions}

The changes in houses category $\mathrm{C}$ and houses completely plastered in the villages, from before and after the interventions were evaluated in a group of 550 houses with complete information (Table 1).

There were increases in houses with good quality complete wall plastering in both El Tule (13.4\%) and La Brea (20.5\%) (Table 2), both of which were significant according to the McNemar test $(\mathrm{p}<0.05)$. There was a $4.1 \%$ (not significant) decrease in the percentage of houses with quality complete plastering in El Sillon, and an 8.7\% (significant) increase in La Perla.

$30 \%$ of households in El Tule (64 out of 215) agreed to use the new plaster formulation, while this percentage was higher in La Brea at 46\% (64 out of 138). The proportion of houses that needed radical improvements was higher in La Brea where $20 \%$ of houses did not have any plastering at all, compared with less than $10 \%$ in El Tule.

\section{Changes in triatomine infestation after interventions}

A total of $202 T$. dimidiata were collected in the domestic and peridomestic environments of the four villages prior to the ecosystemic and traditional interventions (222 including T. nitida) whereas a total of $208 \mathrm{~T}$. dimidiata were collected after the interventions.

The domestic entomological indices, before and after the interventions, indicate reductions in infestation and colonization in the four villages, but slight increases in crowding (Table 3 ). The reduction in infestation was highest in the ecosystemic village of La Brea (a $4.5 \%$ decrease). The 
Figure 1

Percentage of houses by type of improvements reported by owner before intervention, per house category in study area villages. Guatemala, 2004 .

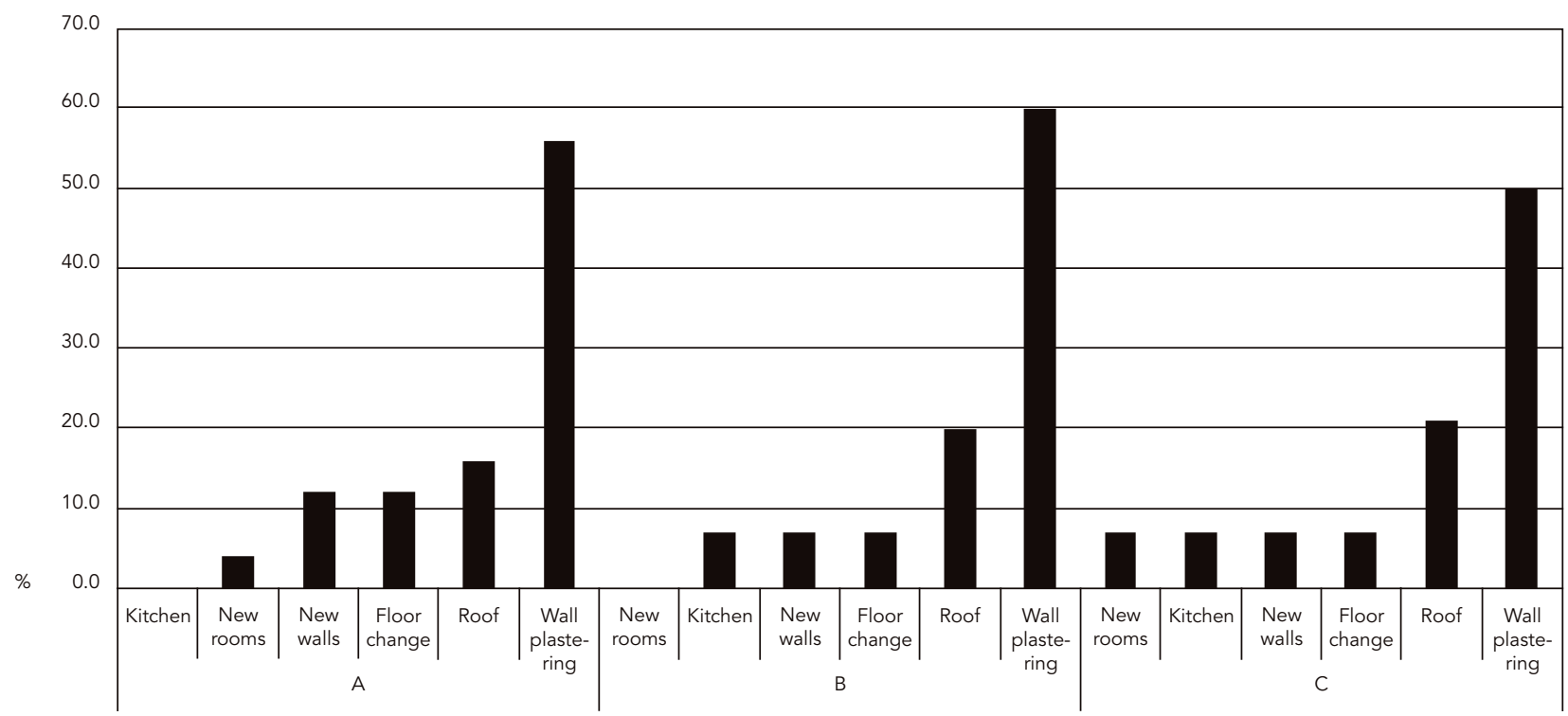

Table 1

Number (and percentage) of houses before and after intervention and change in status (after minus before), by house category per village in ecosystemic and traditional study areas.

\begin{tabular}{|c|c|c|c|c|}
\hline \multirow{3}{*}{$\begin{array}{l}\text { Intervention status/ } \\
\text { House category }\end{array}$} & \multicolumn{4}{|c|}{ Villages } \\
\hline & \multicolumn{2}{|c|}{ Ecosystemic } & \multicolumn{2}{|c|}{ Traditional } \\
\hline & El Tule (\%) & La Brea (\%) & El Sillon (\%) & La Perla (\%) \\
\hline \multicolumn{5}{|l|}{ Before } \\
\hline$A$ & $73(42.4)$ & $17(14.5)$ & $23(15.8)$ & $14(12.2)$ \\
\hline B & $47(27.3)$ & $27(23.1)$ & $51(34.9)$ & $49(42.6)$ \\
\hline C & $52(30.2)$ & $73(62.4)$ & $72(49.3)$ & $52(45.2)$ \\
\hline \multicolumn{5}{|l|}{ After } \\
\hline A & $80(46.5)$ & $28(23.9)$ & $27(18.5)$ & $20(17.4)$ \\
\hline$B$ & $74(43.0)$ & $62(53.0)$ & $49(33.6)$ & 45 (39.1) \\
\hline C & $18(10.5)$ & $27(23.1)$ & $70(47.9)$ & $50(43.5)$ \\
\hline \multicolumn{5}{|l|}{ Change } \\
\hline$A$ & $7(4.1)$ & $11(9.4)$ & $4(2.7)$ & $6(5.2)$ \\
\hline B & $27(15.7)$ & 35 (29.9) & $-2.0(-1.4)$ & $-4.0(-3.5)$ \\
\hline C & $-34.0(-19.8)$ & $-46.0(-39.3)$ & $-2.0(-1.4)$ & $-2.0(-1.7)$ \\
\hline Total houses evaluated & 172 & 117 & 146 & 115 \\
\hline
\end{tabular}


Number (and percentage) of houses before and after intervention, and change in status (after minus before), by house plaster conditions per village in ecosystemic and traditional study areas.

\begin{tabular}{|c|c|c|c|c|}
\hline \multirow{3}{*}{$\begin{array}{l}\text { Intervention status/ } \\
\text { House plastering }\end{array}$} & \multicolumn{4}{|c|}{ Villages } \\
\hline & \multicolumn{2}{|c|}{ Ecosystemic } & \multicolumn{2}{|c|}{ Traditional } \\
\hline & El Tule (\%) & La Brea (\%) & El Sillon (\%) & La Perla (\%) \\
\hline \multicolumn{5}{|l|}{ Before } \\
\hline Quality complete & $85(49.4)$ & $47(40.2)$ & $60(41.1)$ & $18(15.7)$ \\
\hline Low quality complete & $39(22.7)$ & $23(19.7)$ & $46(31.5)$ & $1(0.9)$ \\
\hline Incomplete & $35(20.3)$ & $23(19.7)$ & $16(11.0)$ & $13(11.3)$ \\
\hline No plastering & $13(7.6)$ & $24(20.5)$ & $24(16.4)$ & $83(72.2)$ \\
\hline \multicolumn{5}{|l|}{ After } \\
\hline Quality complete & $108(62.8)$ & $71(60.7)$ & $54(37.0)$ & $28(24.3)$ \\
\hline Low quality complete & $24(14.0)$ & $15(12.8)$ & $54(37.0)$ & $3(2.6)$ \\
\hline Incomplete & $32(18.6)$ & $22(18.8)$ & $25(17.1)$ & $12(10.4)$ \\
\hline No plastering & $8(4.7)$ & $9(7.7)$ & $13(8.9)$ & $72(62.6)$ \\
\hline \multicolumn{5}{|l|}{ Change } \\
\hline Quality complete & $23(13.4)$ & $24(20.5)$ & $-6.0(-4.1)$ & $10(8.7)$ \\
\hline Low quality complete & $-15.0(-8.7)$ & $-8.0(-6.8)$ & $8(5.5)$ & $2(1.7)$ \\
\hline Incomplete & $-3.0(-1.7)$ & $-1.0(-0.9)$ & $9.0(6.2)$ & $-1.0(-0.9)$ \\
\hline No plastering & $-5.0(-2.9)$ & $-15.0(-12.8)$ & $-11.0(-7.5)$ & $-11.0(-9.6)$ \\
\hline Total houses evaluated & 172 & 117 & 146 & 115 \\
\hline
\end{tabular}

Quality complete: all walls plastered; low quality complete: all walls with plastering in bad conditions; incomplete: some walls plastered (either good or low quality); no plastering: bare walls.

Table 3

Before and after the interventions domestic entomological indices for the four villages and Trypanossoma cruzi infection index for all Triatoma dimidiata (infection index includes bugs collected in both domestic and peridomestic environments).

\begin{tabular}{|c|c|c|c|c|c|c|c|c|}
\hline & \multicolumn{4}{|c|}{ Ecosystemic } & \multicolumn{4}{|c|}{ Traditional } \\
\hline & \multicolumn{2}{|c|}{ El Tule } & \multicolumn{2}{|c|}{ La Brea } & \multicolumn{2}{|c|}{ El Sillon } & \multicolumn{2}{|c|}{ La Perla } \\
\hline & Before & After & Before & After & Before & After & Before & After \\
\hline Infestation * & 5.1 & 2.5 & 5.2 & 0.7 & 3.1 & 2.6 & 5.2 & 2.1 \\
\hline Colonization ** & 2.8 & 1.5 & 2.2 & 0.7 & 3.1 & 0 & 4.4 & 0.7 \\
\hline Crowding ${ }^{\star \star \star}$ & 4.0 & 5.6 & 1.4 & 2.0 & 4.2 & 1.0 & 1.7 & 1.3 \\
\hline Tr. cruzi infection & 2.8 & 1.5 & 0 & 0 & 6.9 & 0.6 & 4.4 & 0.7 \\
\hline
\end{tabular}

* Infestation index: number of infested houses/total number of houses $\times 100$.

** Colonization index: number of houses with nymphs/total number of houses $x 100$.

*** Crowding index: number of collected bugs/number of infested houses.

reductions in colonization were evident in all villages but only in the traditional village of El Sillon did it reach a zero percent. The crowding index (number of bugs in infested houses) increased in both ecosystemic villages and decreased in both traditional villages. The Tr. cruzi infection index decreased in the four villages.

\section{Changes in the distribution of bugs after inverventions}

Before the interventions, $52.4 \%$ of bugs were domestic in the ecosystemic villages, and $33.3 \%$ were domestic in the traditional villages (Table 4). After the interventions, these percentages had drastically reduced to $17.5 \%$ and $2.3 \%$, respec- 
Number (and percentage) of Triatoma dimidiata collected in the domestic and peridomestic environments in the four villages, before and after the interventions.

\begin{tabular}{|c|c|c|c|}
\hline $\begin{array}{l}\text { Intervention status/ } \\
\text { Village }\end{array}$ & Domestic (\%) & Peridomestic (\%) & Total \\
\hline \multicolumn{4}{|l|}{ Before } \\
\hline \multicolumn{4}{|l|}{ Ecosystemic } \\
\hline El Tule & $44(48.4)$ & $47(51.6)$ & 91 \\
\hline La Brea & 10 (83.3) & $2(16.7)$ & 12 \\
\hline Total & $54(52.4)$ & $49(47.6)$ & 103 \\
\hline \multicolumn{4}{|l|}{ Traditional } \\
\hline El Sillon & $21(52.5)$ & $19(47.5)$ & 40 \\
\hline La Perla & $12(20.3)$ & $47(79.7)$ & 59 \\
\hline Total & $33(33.3)$ & $66(66.7)$ & 99 \\
\hline \multicolumn{4}{|l|}{ After } \\
\hline \multicolumn{4}{|l|}{ Ecosystemic } \\
\hline El Tule & $28(22.0)$ & 99 (78.0) & 127 \\
\hline La Brea & $2(4.5)$ & $42(95.5)$ & 44 \\
\hline Total & $30(17.5)$ & $141(82.5)$ & 171 \\
\hline \multicolumn{4}{|l|}{ Traditional } \\
\hline El Sillon & $4(57.1)$ & $3(42.9)$ & 7 \\
\hline La Perla & $4(13.3)$ & $26(86.7)$ & 30 \\
\hline Total & $8(2.3)$ & $29(97.7)$ & 37 \\
\hline
\end{tabular}

tively. Thus, even though the number of bugs collected before and after the intervention was similar (around 200) the spatial distribution was shifted to the peridomestic environments that became the most important reservoirs holding $82.5 \%$ of the bugs in the ecosystemic villages and $97.7 \%$ in the traditional villages.

\section{Discussion}

The finding that the local people in all villages already have a tendency to improve their houses mainly by plastering was very important to develop the intervention strategy for the ecosystemic approach. Community knowledge of local materials for construction purposes was astonishing, with more then 36 samples of materials taken from one village to the University Laboratory, and the more abundant materials used in the new mixtures.

The inhabitants of La Brea and El Tule villages showed the research group the local materials that they use for the "revocado" and after laboratory testing, the best materials and mixtures were selected. This work was the basis for the development of a new plastering formulation that was actively promoted in the ecosystemic vil- lages. After the final survey to evaluate the results of the interventions in the ecosystemic villages, the use of the new mixture was recommended to the population in the traditional villages to provide them with the opportunity to improve their houses.

The changes were achieved by intensive work with the community; house to house visits were essential 22. While women were in charge of plastering, men and children were responsible for bringing the mud and sand to the house. The communities acknowledged that with their house improvements, the risk of infection from Chagas disease decreased. In addition, changes to their houses influenced the inhabitants' perceptions and feelings towards their way of living and some female householders began to improve their dirt floors, without influence from the researchers. This was in contrast to the results obtained in Costa Rica, where house improvements were achieved through environmental management, but researchers were responsible for carrying out the changes 12 .

Acknowledging and accepting responsibility for the main determinants of Chagas disease transmission on the part of communities is the first step towards control and prevention interventions. Community participation is not easy 
to achieve, and respect for their traditional materials and methods was fundamental in guaranteeing acceptance of the new plastering. Our experience reveals that the understanding of cultural practices was critical to the introduction of new technologies. The fact that women made the improvements to their own houses reinforces our expectation that the new technology (long lasting) and knowledge will be introduced and disseminated, particularly since women play a key role in house improvements in other areas of Guatemala (Santa Rosa, Jalapa, Chiquimula), as well as in Honduras and El Salvador.

There was an overall improvement in cleanliness and comfort in the houses in the ecosystemic villages (Table 1). In El Tule and La Brea, category $\mathrm{C}$ houses decreased and category $\mathrm{A}$ and $\mathrm{B}$ houses increased. There was a $19.8 \%$ decrease in category $\mathrm{C}$ houses in El Tule and a 39.3\% decrease in la Brea, both significant according to the McNemar test $(\mathrm{p}<0.05)$. There were $1.4 \%$ and $1.7 \%$ decreases in category $\mathrm{C}$ houses in El Sillon and La Perla, respectively; however these decreases were not significant. These results indicate that there was a significant reduction in the percentage of houses with the worst risk conditions in the ecosystemic treatment villages.

The sustainability of improvements is related to the empowerment of communities in acquiring capacities to solve their own problems, and the availability of appropriated technologies and other resources (economic and knowledge based) which provoked new feelings towards the appearance of their houses, meaning that owners continue with improvements, exceeding the researchers' expectations.

The ecosystemic and traditional control strategies applied in this study were both successful in lowering $T$. dimidiata infestations. A few months after the spraying, all villages had less infested houses and a smaller number of domestic bugs were collected after the control intervention. The difference between the two strategies was in the significant improvement in the hygiene and construction conditions and in the location of the bugs collected after the intervention. Bugs were collected in both treatments after the intervention: in the houses where the ecosystemic approach was applied, there was an increase of insects collected (293\%), but in fewer (two) peridomestic ecotopes; while in those houses in which the traditional approach was used, there was a decrease in the amount of bugs collected (43\%) in the peridomestic environments. This phenomenon is reflected in the crowding index (number of bugs in one house) that increased in the ecosystemic approach and decreased in the traditional one. It means that after the ecosystemic treatment we have less number of peri domestic environments infested, but with a greater number of bugs (one improvised chicken coop with 64 bugs that belongs to a Category A house).

We believe that the reduction of domestic habitats available for the bugs inside the houses limited the possibilities for bugs to find shelter outside the houses. The high availability of animal enclosures and other peridomestic microhabitats in the Ecosystemic villages allowed the bugs to stay in the domestic surroundings: we observed high numbers of bugs in an improvised chicken coop made of spare blocks and a pig corral made of deteriorated adobes. The movement of $T$. dimidiata between domestic and peridomestic environments has been suggested by the identification of blood from peridomestic animals from bugs collected inside houses in Costa Rica 3 and was genetically confirmed in Colombia 5 . These observations reveal the importance of developing a strategy to control vector populations in the peri-domicile, as well as the need to improve changes in remaining category $\mathrm{C}$ houses, otherwise non improvement could aggravate the vulnerability of those families.

Schofield 23 estimated that with only two surviving T. infestans in a domestic population, it will take only 368 days for the population to reach $90 \%$ of its original infestation level. We can speculate what will occur under these scenarios in the villages if no other spraying is applied. The reduced domestic populations will likely increase because with low bug densities, more individuals will reach ideal nutritional status and females will show an increase in longevity and fertility ${ }^{23}$. In the case of $T$. dimidiata, a single female can survive from 5 months to one year, with a daily rate of oviposition of ten to 31 eggs for a production of 1,000 eggs in its lifespan 24 . There is not much information available regarding other population parameters for $T$. dimidiata but we can deduce that the maximum populations reached in a specified environment will be in the low hundreds, a fact that can be compared to the average 187 bugs found in three demolished houses in Guatemala 25.

The peridomicile is a diverse and dynamic environment that offers many possibilities for shelter and blood sources for the triatomine bugs. During this study it was often observed that construction materials stacked by the inhabitants sheltered large colonies of $T$. dimidiata. Adobes, roof tiles or floor tiles house as many as 29 bugs. Other more intuitive shelters with more readily available blood sources included chicken coops and pig sties. In the ecosystemic villages, a total of 97 bugs were found in a pig sty and a chicken 
coop, accounting for $56.7 \%$ of the total collections in those villages.

An increase in the number of bugs collected outside the houses was observed in the ecosystemic villages. These villages had more complex peri-domiciles than the traditional villages, because more houses had chicken coops made from adobe walls, a higher diversity of domesticated animals and a tendency to accumulate construction materials (tiles, adobes, blocks, and floor tiles); all of these were detected as microenvironments preferred by T. dimidiata in the peridomicile.

We have followed the infestation situation in La Brea village since 2002; in that year, 37\% of houses were infested with T. dimidiata. The infestations were lowered by several rounds of insecticide spraying (four times), showing that T. dimidiata re-infestation is a generalized phenomenon 9,11 in the Jutiapa area and house improvements should be at the center of strategies for Chagas disease control in Central America 26. The minimal cost of spraying one house in Guatemala is US $\$ 8.00$ 8. We estimate that completely plastering an average sized house with the new formulation will cost around US $\$ 30.00$. The improved durability of the new plastering formulation (three to five years according to the engineers) will reduce economic investments in the long run and prevent $T$. dimidiata infestations. A combination of spraying and house improvements may lead to a long term sustainable vector control. It would be recommendable to carry out a cost-benefit study to estimate how the improved plastering could reduce the frequency of wall repairs.

The recommended goal for the control of T. dimidiata in Central America is to reduce infestation levels to $5 \%$ or less 27 . This goal was achieved with a single insecticide spraying in very few villages in Jutiapa, but in some of the same villages infestations doubled a couple of years after the insecticide application ${ }^{11}$. Schofield indicates that reductions of triatomine populations are followed by increases due to reproduction of the surviving bugs, or by migration of bugs from untreated locations 23 . The complexity of peridomestic environments, the community tendency of changing or moving the peridomestic ecotopes, the diversity of animal blood sources and seasonal climatic variations are issues that should be taken into consideration when designing a control strategy for the peridomestic bugs.

Since the ecosystemic approach includes some environmental and poverty mitigation interventions such as the reforestations of backyards with fruit trees and the promotion of nonstinging bees, the community feels that the benefits are not limited to health issues but include holistic, lifestyle benefits.

Sustainable vector control through the integration of strategies and efforts on house improvements, community participation, a better environment and quality of life, increases in sources of work in rural areas and integrated education on health issues may, in the long term, succeed in the maintenance of T. dimidiata control.

The ecosystemic approach with the holistic implementation of interventions such as household improvements, reforestation of backyards, promotion of non-stinging bees, poverty reduction, insecticide application, gender consideration, awareness of community structures, interactions of stakeholders and promotion of community participation proved successful in reducing the risk of Chagas disease transmission. 


\section{Resumo}

A degradação ou ausência de reboco nas paredes e as condições higiênicas deficientes são os fatores de risco mais importantes para a infestação intradomiciliar por Triatoma dimidiata na Guatemala. Realizamos um estudo transdisciplinar sobre infestação por T. dimidiata, higiene intradomiciliar e condições de construção. O estudo destacou as questões de materiais locais e aspectos culturais (inclusive papéis de gênero) que poderiam levar a melhorias nas condições das paredes no longo prazo. Formulou-se uma nova mistura de gesso para paredes, após estudos de laboratório sobre materiais de construção com base em recomendações dos residentes locais. Foram estudados quatro vilarejos com infestação por T. dimidiata que havia persistido mesmo após aplicação de inseticida. Em duas comunidades, foi implementada uma abordagem ecossistêmica, e os residentes implementaram melhorias nas paredes e no saneamento domiciliar, com o apoio da equipe interdisciplinar (intervenção ecossistêmica). Nas duas outras comunidades, adotou-se uma estratégia de controle com base na aplicação de inseticida (intervenção tradicional). Ambas as intervenções levaram a uma redução na infestação por T. dimidiata, mas apenas a abordagem ecossistêmica produziu melhorias importantes nas condições de moradia (saneamento e revestimento das paredes) capazes de prevenir a re-infestação por T. dimidiata no longo prazo.

Doença de Chagas; Participação Comunitária; Saneamento de Residências; Habitação

\section{Contributors}

D. M. Bustamante contributed on study design, data analysis and interpretation, and manuscript preparation. C. Monroy contributed on study design, data acquisition, and manuscript preparation. S. Pineda collaborated on data analysis, data acquisition, and manuscript arrangement. A. Rodas and X. Castro were responsible for data collection and analysis; V. Ayala and J. Quiñónes for data collection and corrections to the manuscript; and B. Moguel for the database, data collection and organizing the tables.

\section{Acknowledgments}

This work was supported by the International Development Research Centre (IDRC) under its Ecosystem Approaches to Human Health Program Initiative project 101812. We are grateful to the people in all the villages for welcoming us and collaborating in this study. We appreciate the hard work of all the members of the research team and the support of the personnel at Jutiapa's Health Department, as well as Ranferi Trampe and Leonicio Revolorio for their contribution towards the fieldwork.

\section{References}

1. Panzera F, Ferrandis I, Ramsey J, Ordonez R, Salazar-Schettino PM, Cabrera M, et al. Chromosomal variation and genome size support existence of cryptic species of Triatoma dimidiata with different epidemiological importance as Chagas disease vectors. Trop Med Int Health 2006; 11:1092-103.

2. Petana WB. American trypanosomiasis in British Honduras. X. Natural habitats and ecology of Triatoma dimidiata (Hemiptera, Reduviidae) in el Cayo and Toledo districts and the prevalence of infection with Trypanosoma (Schizotrypanum) cruzi in the wild caught bugs. Ann Trop Med Parasitol 1971; 65:169-78.

3. Zeledón R, Solano G, Zuñiga A, Swartzwelder JC. Biology and ethology of Triatoma dimidiata (Latreille, 1811). III. Habitat and blood sources J Med Entomol 1973; 10:363-70.
4. Monroy C, Bustamante DM, Rodas A, Enriquez E, Rosales R. Habitats, dispersion and invasion of sylvatic Triatoma dimidiata (Hemiptera: Reduviidae: Triatominae) in Peten, Guatemala. J Med Entomol 2003; 40:800-6.

5. Ramirez CJ, Jaramillo CA, Delgado M, Pinto N, Aguilera G, Guhl F. Genetic structure of sylvatic, peridomestic and domestic populations of Triatoma dimidiata (Hemiptera: Reduviidae) from an endemic zone of Boyaca, Colombia. Acta Trop 2005; 93:23-9.

6. Schofield CJ. Evolucion y control del Triatoma dimidiata. In: Organización Panamericana de la Salud, editor. Taller para el establecimiento de pautas técnicas en el control de Triatoma dimidiata. San Salvador: Organización Panamerica de la Salud: 2002. p. 12-8. (Document OPS/HCP/HCT/214/02). 
7. Reunión de la Comisión Intergubernamental de la Iniciativa de Centroamérica y Belize para la Interrupción de la Transmisión Vectorial de la Enfermedad de Chagas por Rhodnius prolixus, Disminución de la Infestación Domiciliaria por Triatoma dimidiata y Eliminación de la Transmisión Transfusional del Trypanosoma cruzi. Guatemala: Organización Panamericana de la Salud; 1999. (OPS/HCP/HCT/145/99).

8. Nakagawa J, Cordon-Rosales C, Juarez J, Itzep C, Nonami T. Impact of residual spraying on Rhodnius prolixus and Triatoma dimidiata in the Department of Zacapa in Guatemala. Mem Inst Oswaldo Cruz 2003; 98:277-81.

9. Nakagawa J, Hashimoto K, Cordon-Rosales C, Juarez JA, Trampe A, Marroquin L. The impact of vector control on Triatoma dimidiata in the Guatemalan department of Jutiapa. Ann Trop Med Parasitol 2003; 97:289-98.

10. Dumonteil E, Ruiz-Piña H, Rodríguez-Félix E, Barrera-Perea M, Ramirez-Sierra, MJ, Rabinovich IE, et al. Reinfestation of houses by Triatoma dimidiata after intradomicile insecticide application in the Yucatan peninsula, Mexico. Mem Inst Oswaldo Cruz 2004; 99:253-6.

11. Hashimoto K, Cordon-Rosales C, Trampe A, Kawabata $M$. Impact of single and multiple residual sprayings of pyrethroid insecticides against Triatoma dimidiata (Reduviiade; Triatominae), the principal vector of Chagas disease in Jutiapa, Guatemala. Am J Trop Med Hyg 2006; 75:226-30.

12. Zeledón R, Rojas JC. Environmental management for the control of Triatoma dimidiata (Latreille, 1811), (Hemiptera: Reduviidae) in Costa Rica: a pilot project. Mem Inst Oswaldo Cruz 2006; 101: 379-86.

13. Dorn PL, Melgar S, RouzierV, Gutierrez A, Combe C, Rosales $\mathrm{R}$, et al. The Chagas vector, Triatoma dimidiata (Hemiptera:Reduviidae), is panmictic within and among adjacent villages in Guatemala. J Med Entomol 2003; 40:436-40.

14. Tabaru Y, Monroy M, Rodas A, Mejia M, Rosales R. The geographical distribution of vectors of Chagas disease and populations at risk of infection in Guatemala. Medical Entomology and Zoology 1999; 50:9-17.

15. Monroy C, Rodas A, Mejía M, Rosales R, Tabaru Y. Epidemiology of Chagas disease in Guatemala: infection rate of Triatoma dimidiata, Triatoma nitida, and Rhodnius prolixus (Hemiptera, Reduviidae) with Trypanosoma cruzi and Trypanosoma rangeli (Kinetoplastida, Trypanosomatidae). Mem Inst Oswaldo Cruz 2003; 98:305-10.

16. Rizzo NR, Arana BA, Diaz A, Cordon-Rosales C, Klein RE, Powell MR. Seroprevalence of Trypanosoma cruzi infection among school-age children in the endemic area of Guatemala. Am J Trop Med Hyg 2003; 68:678-82.
17. Monroy C, Rodas A, Mejia M, Tabaru Y. Wall plastering and paints as methods to control vectors of Chagas disease in Guatemala. Medical Entomology and Zoology 1998; 49:187-93.

18. WHO Expert Committee on the Control of Chagas Disease. Control of Chagas disease. Second report of the WHO Expert Committee. Geneva: World Health Organization; 2002. (WHO Technical Report Series, 905).

19. American Association of State Highway and Transportation Officials. Standard specifications for transportation materials and methods of sampling and testing: standard method of test for sieve analysis of fine and coarse aggregates. Washington DC: American Association of State Highway and Transportation Officials; 1994.

20. Centre Scientifique et Technique du Batiment. Certification des enduits monocouches d'impermebilisation Modalités d'essais. Paris: Centre Scientifique et Technique du Batiment; 1993. (Cahier du CSTB, 1777).

21. Agresti A. An introduction to categorical data analysis. New York: John Wiley \& Sons; 1996.

22. Dias JPC. La comunidad y el control de la enfermedad de Chagas. Integración, rol, supervisión y evaluación de su participación. In: Organización Panamericana de la Salud, editor. Grupo de trabajo OPS para consulta en planificación operativa, estrategia y evaluación de etapas avanzadas de control antivectorial de la enfermedad de Chagas. Montevideo: Oraganización Panamericana de la Salud; 2001.

23. Schofield CJ. Population dynamics and control of Triatoma infestans. Ann Soc Belge Med Trop 1985; 65:149-64.

24. Zeledón R, Guardia VM, Zuñiga A, Swartzwelder JC. Biology and ethology of Triatoma dimidiata (Latreille, 1811). II. Life span of adults and fecundity and fertility of females. J Med Entomol 1970; 7:462-9.

25. Monroy C, Mejia M, Rodas A, Rosales R, Horio H, Tabaru Y. Comparison of indoor searches with whole house demolition collections of the vectors of Chagas disease and their indoor distribution. Medical Entomology Zoology 1998; 49:195-200.

26. Briceño-León R. El rol de la vivienda Sana. In: Organización Panamericana de la Salud, editor. Taller para el establecimiento de pautas técnicas en el control de Triatoma dimidiata. San Salvador: Organización Panamericana de la Salud; 2002. p. 19-20.

27. Yamagata Y, Nakagawa J. Control of Chagas disease. Adv Parasitol 2006; 61:130-65.

\section{Submitted on $24 /$ Oct $/ 2007$}

Final version resubmitted on 03/Apr/2008

Approved on 08/Apr/2008 